\title{
Subretinal neovascularisation and snow banking in a case of sarcoidosis: case report*
}

\author{
VICTOR PELLEGRINI,' SHIGEAKI OHNO,' SHIGETO HIROSE,' \\ HIDEHIKO MATSUDA,' AND YOHMEI HIRAGA?
}

From the 'Department of Ophthalmology, Hokkaido University School of Medicine, and the ${ }^{2}$ Department of Respiratory Disease, Hospital of Japanese National Railways, Sapporo, Hokkaido 060, Japan

SUMMARY A 49-year-old Japanese man presented with chronic granulomatous uveitis in his left eye. Later he developed macular subretinal neovascularisation. The chest $x$-ray showed bilateral hilar lymphadenopathy. Bronchoscopy and gallium-67 scanning were positive, PPD skin test negative, and serum angiotensin converting enzyme (ACE) levels increased. Ophthalmoscopy and fluorescein angiography of the left eye showed perivasculitis, retinochoroidal exudates, snow banking, and vitreous opacity. On these findings, the diagnosis of sarcoidosis was made. Treatment was based on topical corticosteroids, mydriatics, beta blockers, and oral carbonic anhydrase inhibitors. After 15 months the visual acuity decreased in the left eye, and a neovascular membrane was observed in the macula. Fluorescein angiography confirmed subretinal neovascularisation. Almost two years later the patient still has the neovascular membrane in his left eye.

Sarcoidosis is a granulomatous systemic disease with various clinical features. Among them we can frequently find lesions of the lungs, skin, and eyes. ${ }^{1}$ It may commonly present with chronic granulomatous anterior uveitis, vitreous opacities, retinal vasculitis, and chorioretinal involvement. But there have been few reports of retinal or subretinal neovascularisation $^{2}$ and pars planitis ${ }^{3}$ associated with sarcoidosis.

The purpose of this paper is to present two unusual findings-macular subretinal neovascularisation and snow banking - which were encountered in a patient with ocular sarcoidosis.

\section{Case report}

A 49-year-old man was referred to the Uveitis Survey Clinic of the Hokkaido University Hospital on 22 November 1982 because of decreased vision and floating spots in his left eye. He suffered from acute hepatitis in November 1981, but he had had no ocular disease before.

Correspondence to Dr S Ohno, Department of Ophthalmology, Hokkaido University School of Medicinc, N-15, W-7, Kita-ku, Sapporo, Hokkaido (060), Japan.

* Part of this paper was presented by Dr Pellegrini at the 131st mecting of the Hokkaido Ophthalmological Society on 21 October 1984.
On initial ophthalmological examination his corrected visual acuity was 1.0 in the right eye and 0.4 in the left eye. Applanation tonometry showed 20 $\mathrm{mmHg}$ in the right eye and $22 \mathrm{mmHg}$ in the left eye. The anterior chamber of the right eye was clear, with no flare and cells. In the left eye the anterior chamber showed $1+$ flare and $3+$ cells, with medium sized keratic precipitates on the corneal endothelium. The right eye was normal on ophthalmoscopic examination, and there was no sign of intraocular inflammation. The left eye showed $2+$ vitreous opacities, cystoid macular oedema, perivasculitis, retinochoroidal exudates, and marked snow banking in the inferior periphery of the fundus. The optic disc was reddish, with clear margin (Fig. 1,2).

Chest $x$-rays showed bilateral hilar lymphadenopathy (BHL); a skin test to $0.05 \mu \mathrm{g}-0.1 \mathrm{ml}$ of purified protein derivative of tubercle bacillus (PPD) was negative. Serological tests for syphilis were negative, serum complement activity was $43.9 \mathrm{CH} 50$ units per $\mathrm{ml}$, antinuclear antibody titre 10 units, and serum angiotensin converting enzyme (ACE) positive with 42 units per ml. Bronchoscopy showed reticular pattern, with new vessel formation, characteristic of sarcoidosis. Gallium-67 scanning disclosed increased uptake in the parotid, nasopharyngeal, and lung areas (Fig. 3). Based on these data, the diagnosis of sarcoidosis was established. 


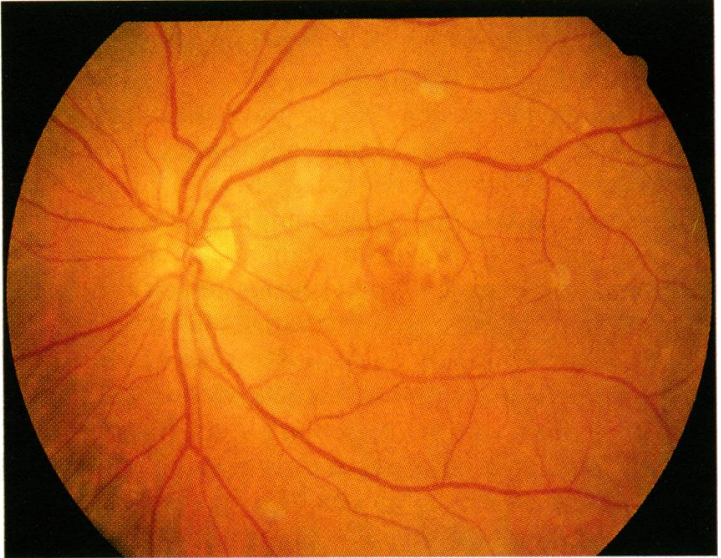

Fig. 1 Fundus picture (posterior pole) of the left eye showing depigmented area and subretinal neovascular membrane in the macula.

The patient was treated with topical corticosteroids, mydriatics, beta blocker agents, and oral carbonic anhydrase inhibitors. Inflammation of the anterior segment of the left eye was well controlled with topical treatment, but the cystoid macular oedema persisted. A posterior sub-Tenon's injection of $40 \mathrm{mg}$ of methylprednisolone acetate was there-

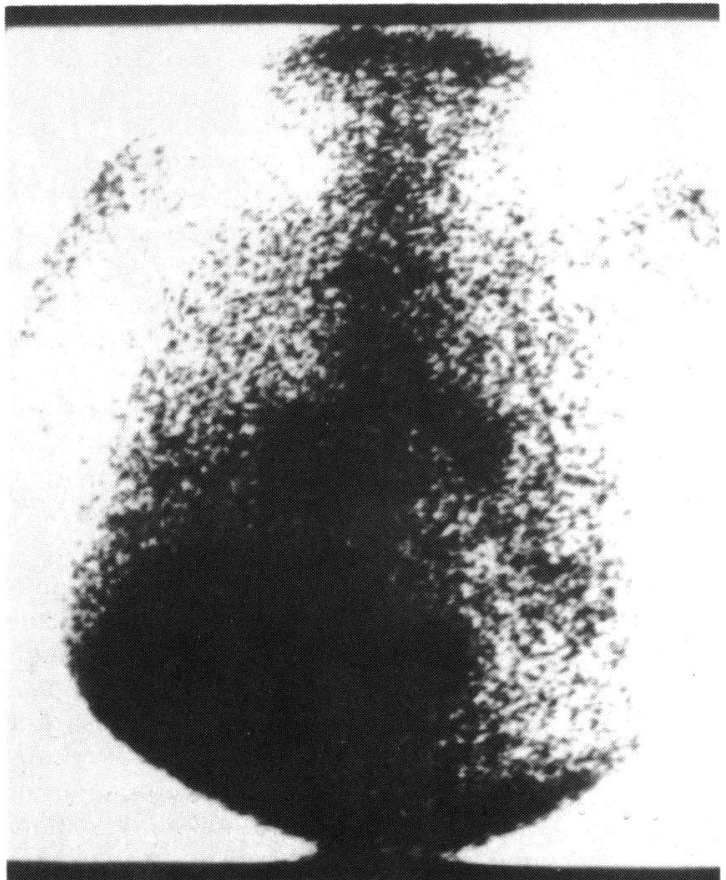

Fig. 3 Gallium-67 scanning disclosing increased uptake in the mediastinal and bilateral hilar areas.

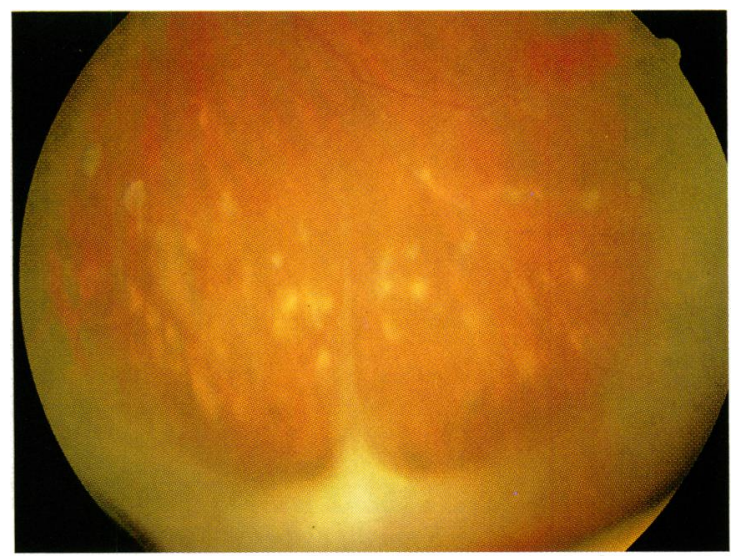

Fig. 2 Fundus picture (inferior periphery) of the left eye showing marked snow banking, retinochoroidal atrophic lesions, and perivascular sheathing.

fore given in the left eye on 7 December 1982. The cystoid macular oedema gradually decreased, and during the following 15 months the patient's condition remained stationary, with visual acuity maintained at about 0.3 and with no clinical exacerbation.

In February 1984, however, he returned to our Uveitis Survey Clinic complaining of decreased vision in his left eye. The left visual acuity was $0 \cdot 1$, and ophthalmoscopic examination showed a neovascular membrane surrounded by a depigmented area in the macula. A small retinal haemorrhage was also detected. Fluorescein angiography showed in the early phase a reticular leakage pattern in the macula, which gradually increased in the late phase. The presence of subretinal neovascularisation was clearly shown in the left macula. No retinal avascular area was noted, but there was a slight leakage from the optic disc and tissue staining of some retinal vessels (Figs. 4, 5).

. Six months later fluorescein angiography was performed again, and the same findings were obtained in the left eye.

\section{Discussion}

Although biopsy has not been performed, various laboratory findings gave us a definite clinical diagnosis of sarcoidosis in this case.

The bilateral hilar lymphadenopathy (BHL) in our case is a characteristic finding. ${ }^{+5}$ Gallium-67 scanning, though the mechanism of the gallium uptake is obscure, is considered to be a sensitive method for detecting systemic as well as ophthalmic changes in sarcoidosis. ${ }^{6}$ Weinreb and Tessler ${ }^{7}$ reported it as being even more sensitive than chest roentgenograms. They also recommended that views of the 


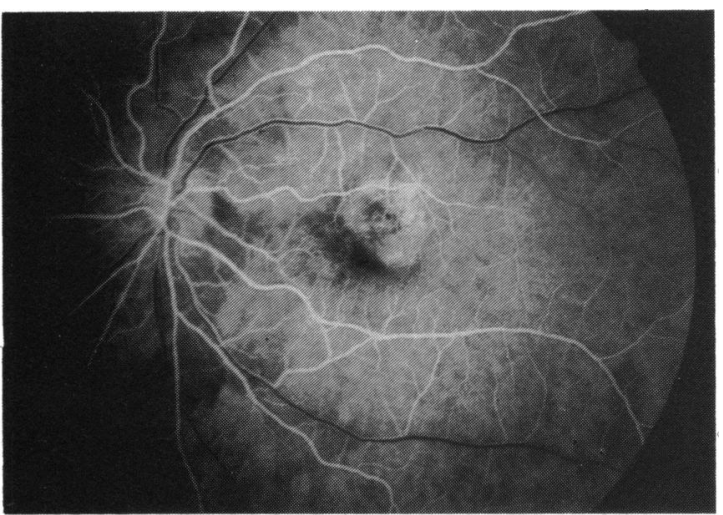

Fig. 4 Fluorescein angiography of the left eye showing leakage of the subretinal neovascularisation (reticular pattern) and slight leakage from the optic disc (25 seconds afterinjection).

head should be included in gallium citrate scans whenever the diagnosis of sarcoidosis is being considered, and stated that over four-fifths of the patients with active sarcoidosis showed increased uptake by the lacrimal glands. In our patient gallium67 scanning disclosed increased uptake not only in the hilar areas of the lung but also in the parotid and nasopharyngeal areas. The PPD skin test, which was negative in this patient, was reported by Obenauf et al. ${ }^{5}$ to be negative in $95.7 \%$ of their cases. Angiotensin converting enzyme, increased in our patient, has been correlated with sarcoidosis by many authors. ${ }^{8-11}$ Bronchoscopic findings have recently been shown to be rather important for the diagnosis of sarcoidosis. Kobayashi et al. ${ }^{12}$ performed bronchoscopy in 130 patients with sarcoidosis and found that $88 \%$ had a network formation of small blood vessels (NFSBV) in the trachea and/or large bronchi

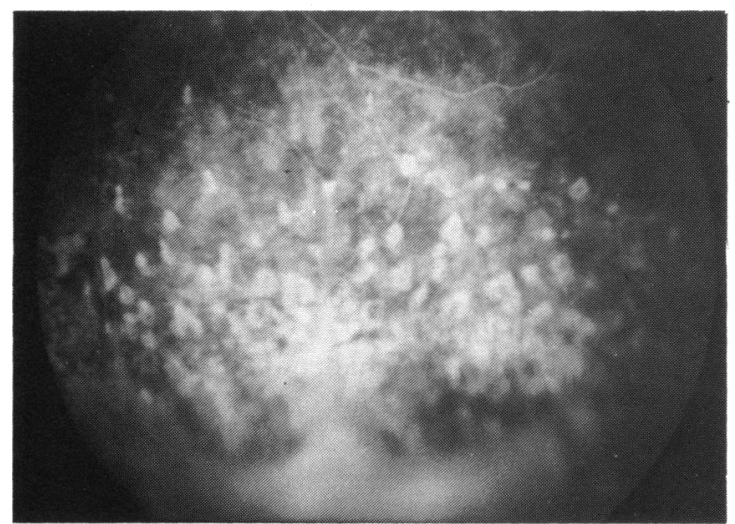

Fig. 5 Fluorescein angiography of the left eye, showing hyperfluorescence of the snow banking and retinochoroidal atrophic lesions (105.5 seconds after injection). as compared with $4 \%$ of the controls. They concluded that these network formations were a characteristic finding in sarcoidosis.

Although Frank and Weiss ${ }^{4}$ have reported a well illustrated case, subretinal neovascularisation in sarcoidosis is rare. This rarity may be partly explained by the fact that some complications in chronic uveitis, such as posterior synechiae of the iris, complicating cataracts, or vitreous opacity, make it difficult to obtain a good fluorescein angiogram. ${ }^{13}$

The exact cause of the proliferation of choroidal vessels is unknown, and no satisfactory experimental model of choroidal neovascularisation has yet been found. Bruch's membrane seems to have an important role, acting as a mechanical barrier that may separate new choroidal vessels from the subpigment epithelial space, and, when it is ruptured, newly formed choroidal vessels will grow through the rents. ${ }^{14}$

Archer and Gardiner ${ }^{15}$ produced experimental choroidal neovascularisation in the rhesus monkey by photocoagulation and suggested that new choroidal vessels are formed by proliferating endothelial cells originating by mitosis in injured and exposed choroidal vessels at photocoagulation sites. Recently, however, Henkind ${ }^{16}$ stated that choroidal neovascularisation does not require breaks in Bruch's membrane, but rather that new vessels can literally dissolve the membrane. He considers that the retinal pigment epithelium produced a factor responsible for inducing the formation of new vessels from the choroid.

Photocoagulation has been proposed as the best means of treating choroidal neovascularisation. ${ }^{14}$ Nevertheless, Hoogstede and Copper ${ }^{13}$ suggested that remission of the subretinal neovascularisation may follow the use of systemic corticosteroids. In our case systemic corticosteroids were not given, because the patient lived far from the hospital and it was difficult to examine him regularly. On the other hand photocoagulation was not performed owing to the foveal localisation of the vasculature and the presence of a subretinal fibrovascular scar that made it difficult to delineate the exact extent of the nets, making photocoagulation a dangerous procedure. Snow banking, a common finding in pars planitis (intermediate uveitis), is rare in patients affected with sarcoidosis. ${ }^{3}$ In our experience ${ }^{17}$ in 95 patients (176 eyes) with ocular sarcoidosis 50 eyes $(28.4 \%)$ had coarse vitreous opacities and $46(26 \cdot 1 \%)$ fine vitreous opacities, but none showed snow banking. But because of their importance in the course of the disease we recommend that subretinal neovascularisation and snow banking should always be carefully sought, as they may sometimes be encountered in association with ocular sarcoidosis. 


\section{References}

1 Yanoff M. Finc BS. Granulomatous inflammation. In: Duanc TD, Jacger EA, cds. Biomedical foundations of ophthalmology. Philadelphia: Harper and Row, 1982: 16-17

2 Hirose S, Ohno S. Argon laser treatment of the retinal neovascularization associated with sarcoidosis. Jpn J Ophthalmol 1984; 28: 356-61

3 Chester GH, Blach RK, Cleary PE. Inflammation in the region of the vitreous base. Pars planitis. Trans Ophthalmol Soc UK 1976; 96: 151-7.

4 Frank KW, Wciss H. Unusual clinical and histopathological findings in ocular sarcoidosis. Br J Ophthalmol 1982; 67: 8-16.

5 Obenauf CD, Shaw HE, Sydnor CF, Klintworth GK. Sarcoidosis and its ophthalmic manifestations. Am J Ophthalmol 1978: 86: $648-55$

6 Karma A, Poukkula A, Ruokonen A. Gallium-67 citrate scanning in patients with lacrimal gland and conjunctival sarcoidosis. Acte Ophthalmol (Kbh) 1984; 62: 549-55.

7 Weinreb RN, Tessler H. Laboratory diagnosis of ophthalmic sarcoidosis. Surv Ophthalmol 1984; 28: 653-64.

8 Ohno S, Nerome K, Takcuchi T, Matsuda H. Studies on serum angiotensin converting enzyme in endogenous uveitis. Nippon Ganka Gakkai Zasshi 1980); 84: 1085-91.

9 Wcinreb RN, O’Donncl JJ, Sandman R, Char DH, Kimura SJ. Angiotensin-converting enzymc in sarcoid uveitis. Invest Ophthalmol Vis Sci 1979; 18: 1285-87.
10) Perkins ES. Ocular sarcoidosis. Editorial. Arch Ophthalmol 1981; 99: 1193.

11 Katz P. Fauci AS. Yeager HJr, Reen BM. Scrum angiotensinconverting enzyme and lysozyme in granulomatous discases of unknown causc. Ann Intern Med 1981: 94: 359-60).

12 Kobayashi T, Hiraga Y, Ogiwara M. et al. Vascular changes in bronchoscopy in patients with sarcoidosis. In: Chréticn J, Marsac J, Salticl JC, cds. Ninth international conference on sarcoidosis and other granulomatous disorders. Paris: Pergamon Press, 1981: 652-4.

13 Hoogstede HALF, Copper AC. A case of macular subretinal ncovascularisation in chronic uveitis probably caused by sarcoidosis. BrJ Ophthalmol 1982; 66: 53()-5.

14 Henkind P. Ocular neovascularization. Am J Ophthalmol 1978: 85: 287-301.

15 Archer DB, Gardiner TA. Electron microscopic features of experimental choroidal neovascularization. Am J Ophthalmol 1981; $91: 433-57$

16 Henkind $P$. Choroidal neovascularization: the pathogenesis is more than a break in Bruch's membranc. Nippon Ganka Gakkai Zasshi 1984; 88 (suppl): 39.

17 Nerome K, Ohno S, Takeuchi T, Matsuda H. Clinical findings of ocular sarcoidosis in Hokkaido University Hospital. Jpn Rev Clin Ophthalmol 1981; 75: 606-9.

Accepted for publication 15 October 1985. 